\title{
Visual Analysis of the Morning News Bumper Program
}

\author{
Adya Mulya Prajana \\ Magister of Design \\ Universitas Komputer Indonesia \\ adyaprajana@gmail.com
}

\begin{abstract}
Television is the most influential electronic media for human life. Besides being heard, it can also be seen. Through television can get information, entertainment, influence, and education. The 2011 Neilsen Indonesia survey, on average, man spends 4.5 hours a day watching television with entertainment and news programs. All television stations in Indonesia at this time make and broadcast news programs with broadcast hours that are on average the same, namely morning, afternoon, evening and night. This makes competition for news programs even tighter to get the attention of the public. In addition to presenting actual, unique and interesting information, in a news television program usually has a bumper. The bumper is an identity, the title of a television program in the form of video, motion graphics or the combination of both. On this occasion, the visual influence of the morning news program television bumper was examined. A case study on the Indonesian Morning Show's morning news program which was broadcast on television NET TV, Indonesia. The research method used was descriptive method used to describe visuals by presenting the results of screenshot into a still image to facilitate analysis. Videos are used to see movement direction and the illusion of visual motion, while still images are used to describe the visual elements found on the bumper. The results of this study are expected to be used to determine the influence of visual elements displayed by a program's bumper.
\end{abstract}

Keywords—visual, bumper, motion graphic, television, design, identity.

\section{INTRODUCTION}

In winning business competition, every television program tries to display interesting programs to be excellent. In addition, television programs try to draw influence through the bumper program. Bumper is a short animation that is at the end of a program, before entering an advertisement, or the beginning of a program when switching from an advertisement to a program, usually there is a program name or logo. Bumper in previous study can segmenting the ongoing flow of television messages into commercial and programming segments [1]. Bumpers can also affect the sensation of human perception and are also able to influence the audience as well as the power of television advertising. In making bumpers besides having to pay attention to the logo the most influencing factor is the visual and motion graphic display, all driven by time. Briefly according to Taylor, motion graphics refers to the displacement of objects from a design. The three main elements of motion graphic are the speed, direction, and path of movement of the object itself. That is why motion graphics are very driven by time [2]. Motion graphics take many forms, but to be considered a motion graphic the elements must incorporate movement or be in motion [3]. Bumpers can be divided into 2 categories according to the placement of the bumper use:

1. Bumper in, the signature to enter the segment in the program.

2. Bumper out, which is the sign that the segment sign is over.

More details in each TV program take place always interspersed with several advertisements, pausing between programs and advertisements where the show bumper [4].

Likewise with the bumper of one of the Indonesian News Morning Program program programs which airs on the morning of 06.05 until 07.25 WIB. A program that displays various updated information packages (hard news, light news, entertainment news) that are delivered in a style that is closer and entertaining. Having a tagline "daily activities will feel incomplete without following the information from the Indonesia Morning Show". The desire to become the best morning news program, the Indonesia Morning Show builds an identity that is displayed through bumper visualization with predetermined identity standards contributed significantly to adding unique news to the daily television news pool and the topics of the unique stories were diverse [5].

Although in each visual appearance, there is a combination of videography and motion graphics, in terms of size, layout, and visual form (still or moving), but there are four keys that become the red thread of a bumper. Landa has described four keys that connect a bumper, namely color, logo, type of letter and shape. In accordance with the Landa theory, the Indonesia Morning Show bumper has rules in terms of colors, logos, type of letters and visual forms displayed [6].

However, describing the visual element of the identity of a television program on a bumper like a moving object is not easy. Of course it is very interesting to analyze the visual elements contained therein.

\section{METHOD}

The research method used descriptive method, describing information about the related visuals bumper of the Indonesia Morning Show and analyze it. Descriptive research method is a problem solving procedure that is investigated by describing the subject or object of research. According to Michael, William B., and Steve Hunka descriptive method is fact finding with the right 
interpretation. This study describes the visuals collected through screenshots of the Indonesia Morning Show video bumper [7].

\section{RESULT}

Population is a generalization area consisting of objects or subjects that have a certain quantity and characteristic set by the researcher to be studied and then drawn conclusions. The video opening of the 34-second Indonesia Morning Show bumper. The author divides the bumper video into 10 images which are categories based on videography and motion graphics. This population is the result of screenshots of the Indonesia Morning Show bumper video because the bumper video is a moving image.

Sampling in this study, using purposive sample technique. This sample aims to take the subject not based on strata or random, but based on the existence of a specific goal [8]. So to determine the sample these are several criteria, namely:

1. The sample is an image contained in the video opening bumper of the Indonesia Morning Show.

2. The sample is an image that is considered attractive.

3. The sample is an image consisting of videography and motion graphic.

The sample that will be used is the result of screenshots taken among the population of nine images, because the sample is considered in accordance with the formulation of the problem and the purpose of this study is to describe the visuals contained in the bumper Indonesia morning show.

\section{DISCUSSION}

To begin this research, it begins with the depiction of the city atmosphere represented by the building in figure 1 .

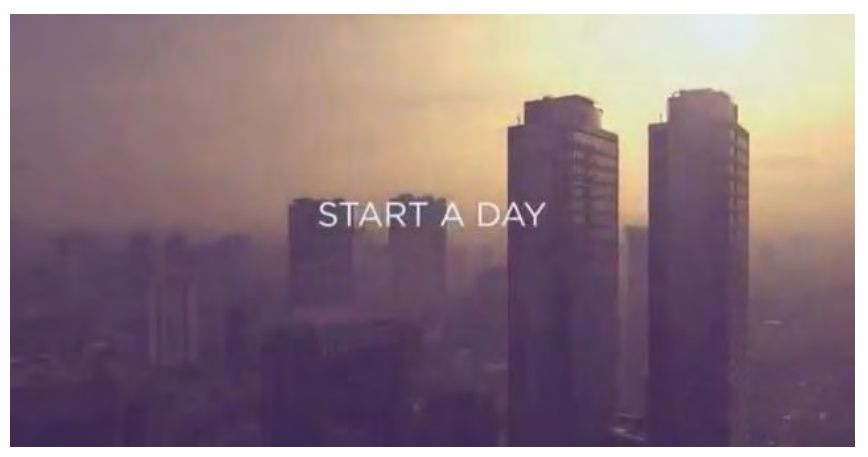

Figure 1. Sample description 00:01 seconds. Source: Video Bumper of Indonesia Morning Show.

Those two tall and sturdy buildings in an urban area are the center of the picture. The city is a resettlement center and population activity that has administrative borders as regulated in legislation and settlements that have demonstrated the nature and characteristics of urban life. The city has three main characteristics, namely having a high population density, the center of all activities, and the main non-agricultural activities. Concentric Theory [9], this theory states that the Central City Region (DPK) or Central Business District (CBD) is a city center that is located right in the middle of the city and in the form of a round that is the center of social, economic, cultural and political life, and is a zone with a high degree of accessibility in a city.

The characteristics of city life shall be as follows:

1. The existence of socio-economic coatings, for example differences in income levels, level of education and type of work.

2. There is social distance and lack of social tolerance among its citizens.

3. There are different assessments of a problem with consideration of differences in interests, situations and conditions of life.

4. City residents generally appreciate time.

5. The way of thinking and acting of the citizens of the city seems more rational and economic principles.

6. Inhabitant are more easily adapted to social change due to openness to outside influences.

7. In general, the urban community is more individual, while the nature of solidarity and mutual cooperation has begun to disappear. (This stereotype then causes city dwellers and migrants to take an indifferent attitude and do not care when interacting with other people. They ignore the fact that city people can also be friendly and polite in interacting).

A building is a physical form of the results of a construction work that integrates with its domicile, part or all of it is above and / or in the land and / or water, which functions as a place for humans to carry out their activities, whether for shelter or residence, religious activities, activities business, social activities, culture, or special activities. Public buildings are buildings that function for the public interest, both in the form of religious functions, business functions, and social and cultural functions.

Behind the building there is the initial light of the rising sun which marks the morning. Morning is the beginning of a day. In Indonesian culture, morning is the period from midnight to around 12.00. Morning time is a term that starts all time in a day, precedes day and night. Morning in the use of daily activities is the time between 01:00 to 10:00.

Then a text "START A DAY" appear with a thin letter and minimalist impression. Text is written using English. English is the most important foreign language studied in Indonesia. English in Indonesia is generally taught as a foreign language. The term foreign language in the field of language teaching is different from the second language. Foreign language is a language that is not used as a communication tool in certain countries where the language is taught. While the second language is a language that is not the main language, it is one of the languages used in general in a country. English as a foreign language changes over time and changes in policy are mostly influenced by economics and politics. This picture as a whole tries to convey the atmosphere of the beginning of the day in a big city with human activities in it.

Next is the depiction of the morning atmosphere at the dining table. Personally through the figure of a man pouring coffee into a cup contained in figure 2 . 


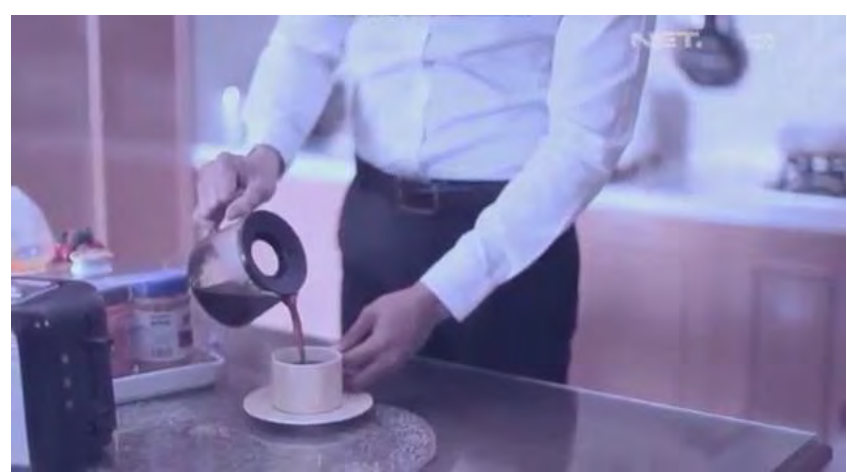

Figure 2. Sample description 00:06 seconds.

Source: Video Bumper of Indonesia Morning Show.

This is a man who wearing a white shirt in a dark gray pants with a belt. The impression captured from the man's figure is very formal, organized and confident in the category of metrosexual men. The Independent. Simpson 1994, Metrosexual Men, young single men with excess income, living and working in urban areas. In its development, the metrosexual concept leads to the lifestyle of modern urban men who earn more and care deeply about their appearance and image.

Still describing the morning atmosphere through the objects that represent activities in the morning. Represented through figure 3 .

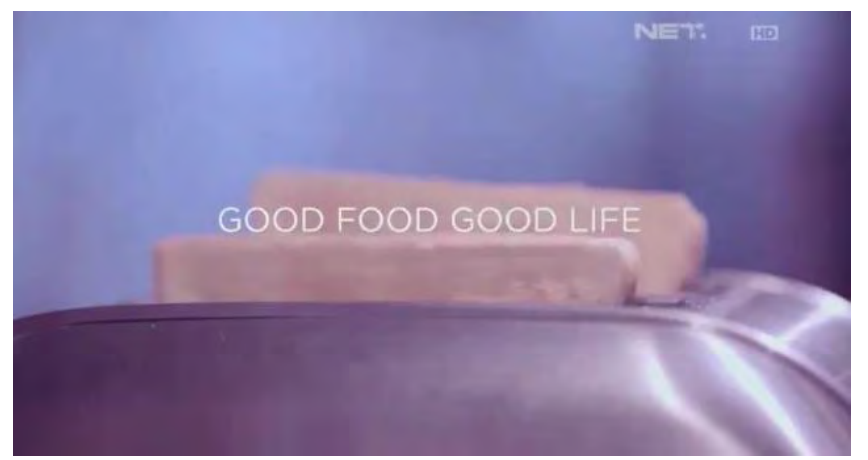

Figure 3. Sample description 00:07 seconds Source: Video Bumper of Indonesia Morning Show.

Then the text "GOOD FOOD GOOD LIFE" appeared. The text uses a bold thin minimalist letter with the previous text using English. The text tries to build a message to the community that eating good food creates a good life.

Visual object focus is the bread that is being baked. Fresh bread is food commonly consumed every morning by the Indonesian people. Fresh bread was originally the food of the people of the Middle East community. Along with the development until now, bread has become a favorite food in various parts of the world. Therefore the Indonesian people are very fond of consuming bread. Fresh bread has a high carbohydrate content so it can withstand hunger and become a substitute for rice during an emergency. Fresh bread is usually the breakfast menu in the morning.

Toaster from stainless material builds visuals with a modern, simple and minimalist impression. Stainless is an iron compound that contains about $10 \%$ chromium which prevents metal rusting. The design uses materials from stainless so there are other effects that are caused, namely the effect of the room seems modern and elegant.

Figure 4 still describes the habits that are carried out in the morning by a man in the present, namely a cup of coffee and reading digital articles.

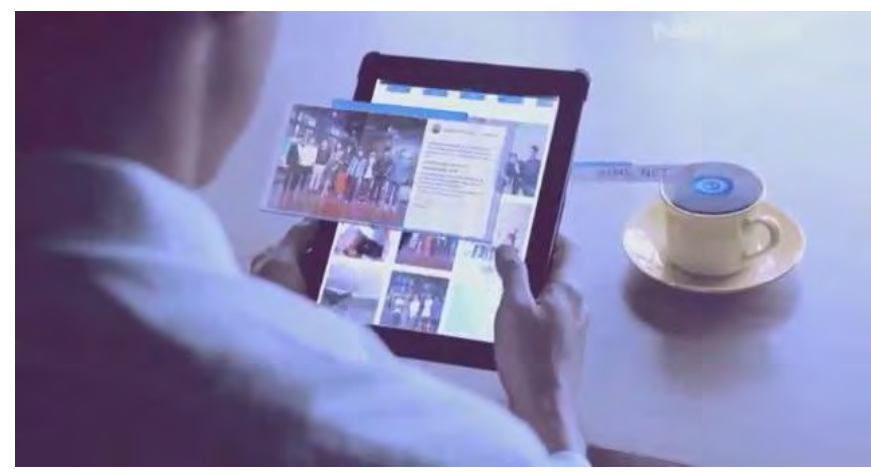

Figure 4. Sample description 00:08 seconds. Source: Video Bumper of Indonesia Morning Show.

After that, we could see a man doing activities in the morning. Seen while drinking coffee while holding gadgets and reading digital newspapers. Digital newspapers are newspapers in electronic format that can be accessed by computers or smart phones. Due to technological developments, newspapers that are only printed, are now available in digital or electronic versions of the printed version.

In addition to digital newspapers visual focus is also seen in cups containing coffee water. A cup of coffee in the morning with a piece of toast can be the opening menu before starting the activity [10]. A cup of bitter black coffee can have a considerable influence on anyone who consumes it. The coffee is stored on a table with an impressive wood texture simple, minimalist and elegant.

Figure 5 shows the next activity of a man's morning daily that is preparation for going to work. Impressed from the office look he was wearing.

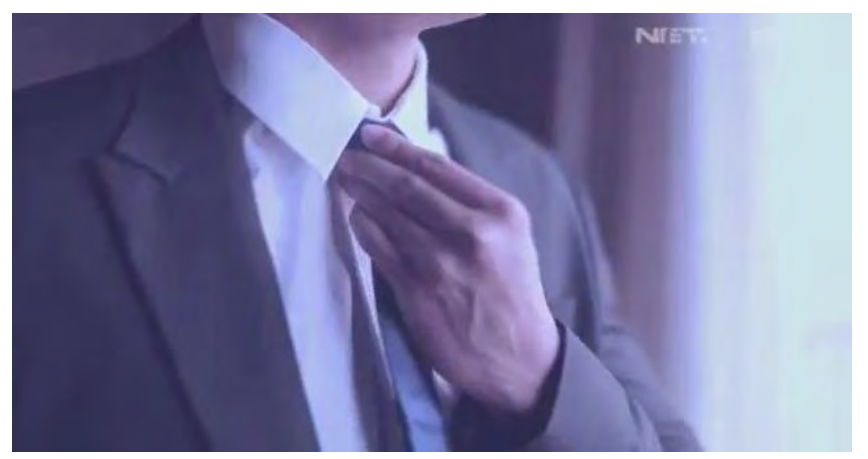

Figure 5. Sample description 00:09 seconds. Source: Video Bumper of Indonesia Morning Show

After that we could see a man using a suit and the tie is preparing to start the activity. Using men's suits for adult men is mandatory, especially for attending formal events, such as meetings with important clients, attending a wedding reception, or when attending a job interview. Being neat and 
professional is the main capital to success. Suits and ties are usually used by people who live in cities.

In figure 6 we can see the activities of urban communities in starting an identical and active day.

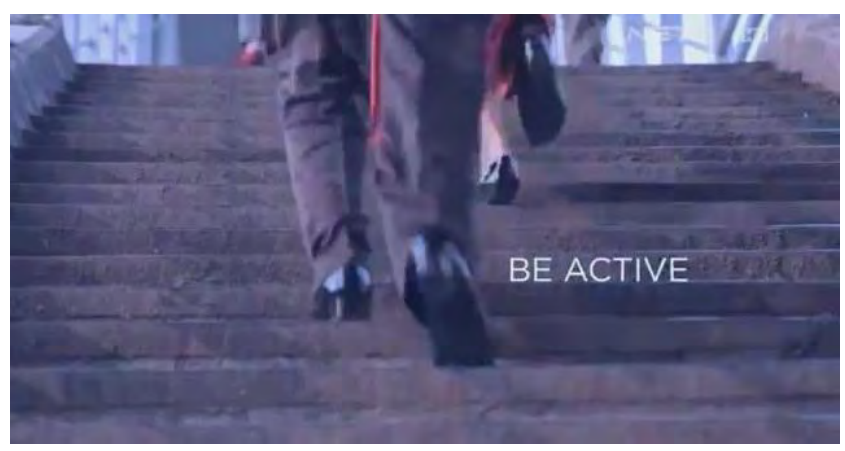

Figure 6. Sample description 00:11 seconds Source: Video Bumper of Indonesia Morning Show

We could see a man is starting his activities walking up the stairs. With the text written "BE ACTIVE" a minimalist thin capital letter using English as the words written in the previous image. The visual was trying to convey an urban man who was energetic focused on pursuing his goals.

The atmosphere of the capital was again illustrated through figure 7 which shows the atmosphere of traffic and affirmation in the writing of Traffic News which means news about traffic jams.

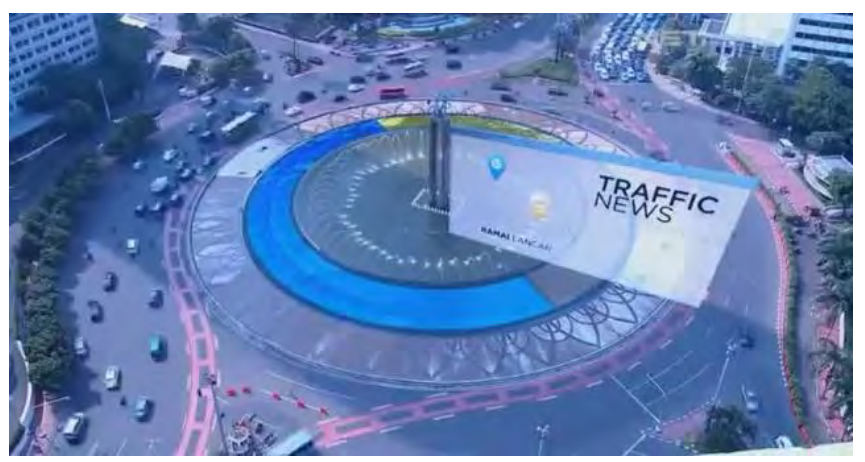

Figure 7. Sample description seconds 00:15 Source: Video Bumper of Indonesia Morning Show

There is a motion graphic box with minimalist text that says "TRAFFIC NEWS". In the box not only text, but there is also a symbol of the place and the color of the traffic jam. Color theory uses traffic color theory. The color of traffic that is universally recognized; to signify a stop is red, be careful which is marked in yellow, and green which means it can walk.

The present situation is also shown through figure 8 which raises social media logos as a depiction of people's lives in the digital era that cannot be separated from social media life.

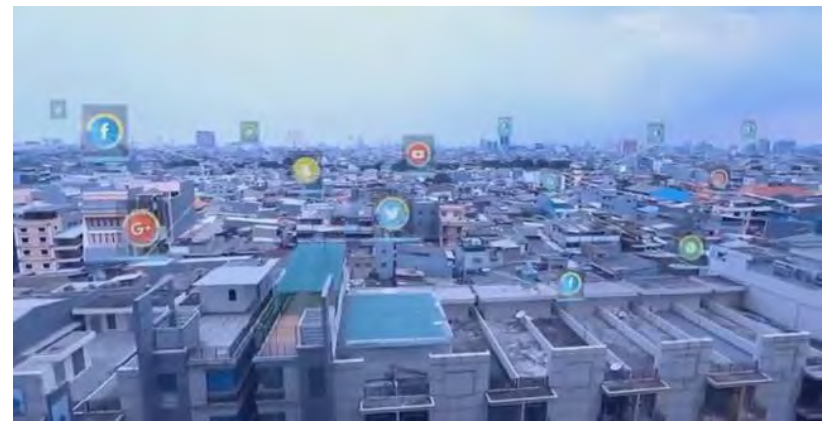

Figure 8. Social Media Logos

Source: Video Bumper of Indonesia Morning Show

There are social media logos such as twitter, facebook, path, google+, whatsapp and others. In the digital era, information can be obtained through various media such as social media. Visual building from above to give a message that the diversity of behavior in urban communities. There are also blue graphic elements following the shape of the building.

Next is a depiction where the location of this activity takes place through a motion map of Indonesia and a visual that depicts gender representing the community.

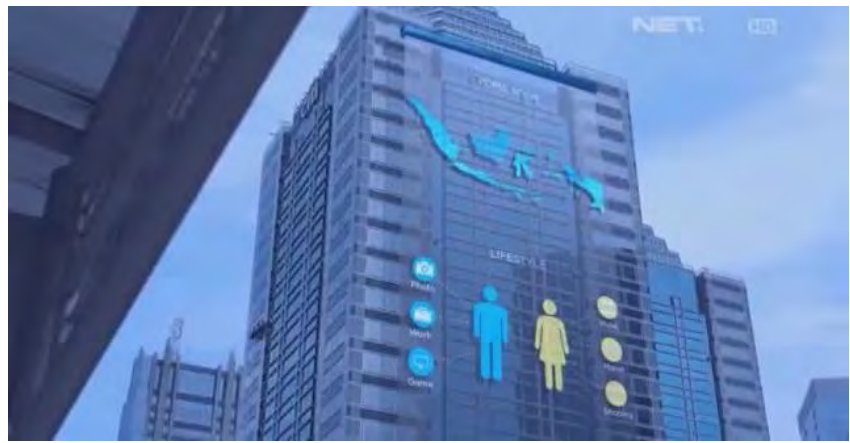

Figure 9. Sample description seconds 00:29 Source: Video Bumper of Indonesia Morning Show

There is a visual building with a motion graphic map of Indonesia that is blue, visual forms resemble men and women and symbols of each activity. The color of men and women is divided into two, men are blue and women are yellow.

Finally, the depiction of urban life is increasingly emphasized by figure 10 which features high buildings and event logos.

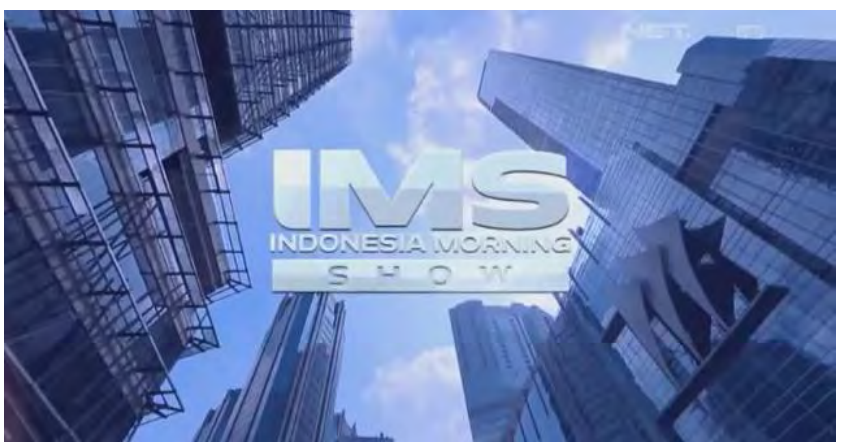

Figure 10. Sample description 00:33 seconds Source: Video Bumper of Indonesia Morning Show 
There is a visual of a tall building with pictures taken from below to build an impression so high and far up that it claws at the sky. Logo of Indonesia Morning Show is shortened to IMS. Made into three lines. The first line of IMS, the second line of Indonesia Morning and the third row of Show are in the box. The letter moves dissolve to solid form the IMS Indonesia Morning Show. The logo looks like stainless to build the impression of simple, modern, minimalist and sturdy.

\section{CONCLUSION}

Through a series of research processes that have been carried out, in the end can answer the formulation of the problem in this study entitled: "Visual Analyst to Morning News TV Opening Bumper Break Program (Case Study to Indonesia Morning Show NET TV)". The problem formulation in this study is motion graphic and videography giving messages in display in accordance with the program concept, namely a program that displays a variety of current information packages (hard news, light news, entertainment news) that are delivered in a style that is closer and entertaining. Having a tagline "daily activities will feel incomplete without following information from the Indonesia Morning Show". The visual appearance, color, shape and appearance of the male figure on the Indonesia Morning Show bumper became the program identity that refers to the identity of NET TV. This can be seen from the NET TV Station ID.

\section{ACKNOWLEDGMENT}

Praise God for His blessings and gifts so that the author can complete this journal entitled Visual Analyst to Morning News TV. Case Bumper Opening Program (Case Study to Indonesia Morning Show NET TV). The author would like to thank all those who have helped in writing this journal.

\section{REFERENCES}

[1] Schleuder, Joan D., Alice V. White, and Glen T. Cameron. "Priming effects of television news bumpers and teasers on attention and memory." Journal of Broadcasting \& Electronic Media 37.4 (1993): 437-452.

[2] Jon Krasner, "Motion graphic design applied history and aesthetics", second edition, 2008.

[3] Musselman, Ryan William. Effect of Ornamentation on the Emotion Response and Perception of Motion Graphics. Diss. Virginia Tech, 2013.

[4] Yael Braha and Bill Byrne, "Creative motion graphic titling for film, video \& the web, 2010.

[5] Bae, Hyuhn-Suhck. "Product differentiation in national TV newscasts: A comparison of the cable all-news networks and the broadcast networks." Journal of Broadcasting \& Electronic Media 44.1 (2000): 62-77.

[6] Robin Landa, Graphic Design Solutions, 2011

[7] Michael, William B., and Steve Hunka. "Chapter IV: Research Tools: Statistical Methods." Review of Educational Research30.5 (1960): 440-486.

[8] Arikunto, Research Prosedure, 2010

[9] Luck, Matthew, and Jianguo Wu. "A gradient analysis of urban landscape pattern: a case study from the Phoenix metropolitan region, Arizona, USA." Landscape ecology 17.4 (2002): 327-339.

[10] Goldstein, Avram, and Sophia Kaizer. "Psychotropic effects of caffeine in man. III. A questionnaire survey of coffee drinking and its effects in a group of housewives." Clinical pharmacology \& therapeutics 10.4 (1969): 477-488. 
